\title{
Author Spotlight: Pamela Milito
}

\section{Pamela Milito ${ }^{1}$}

Accepted: 21 September 2021 / Published online: 21 October 2021

(c) The Author(s), under exclusive licence to Springer Science+Business Media, LLC, part of Springer Nature 2021

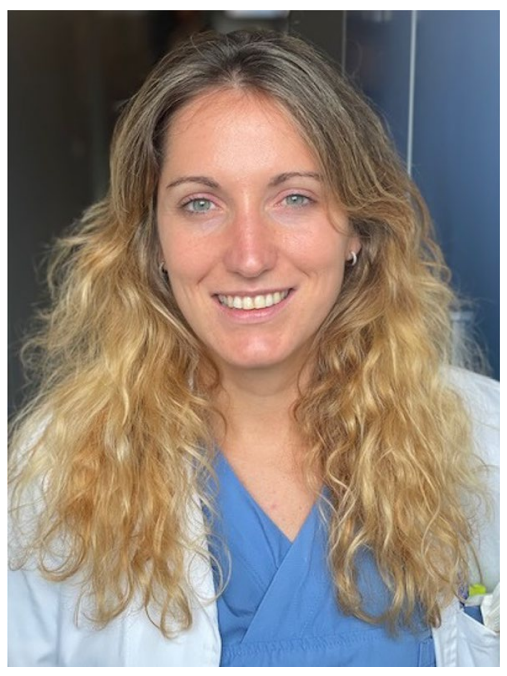

Dr. Pamela Milito received her medical degree from University of Milan in 2015 and she is currently in her final year of residency in General Surgery at IRCCS Policlinico San Donato in Milan, Italy. Her clinical and research interests include upper gastrointestinal malignant and benign diseases. She plans to pursue an academic career following her studies.

Publisher's Note Springer Nature remains neutral with regard to jurisdictional claims in published maps and institutional affiliations.

Pamela Milito

Pamela.milito@unimi.it

1 Università Degli Studi Di Milano, Milan, Italy 